\title{
QUEST \\ Quality Management Tool for Sustainable Urban Mobility
}

\author{
Klára Macsinka \\ Institute of Civil Engineering, Szent István University, Budapest, Hungary \\ macsinka.klara@ybl.szie.hu
}

\begin{abstract}
The article introduces a method to evaluate and develop quality of sustainable mobility planning in European cities. This tool has been worked out by a European Consortium of experts representing 14 countries in Europe. The author - as the Hungarian member and auditor of the Consortium - participated in the project working as an auditor in four Hungarian cities, leading them through the process of the QUEST-method and helping the cities to develop a systematic way of planning sustainable mobility. In the article the process will be shown, advantages, lessons learned, drawbacks and possible future development of the method will be explained.
\end{abstract}

Keywords: Sustainable mobility, QUEST-method, Quality Management Tool, Urban Planning

\section{INTRODUCTION}

Sustainable mobility has an increasing significance in urban transportation planning. Several European projects (for example ELTIS, BYPAD, SMILE, etc.) dealt with possible future scenarios of green mobility, addressing less travel by private cars and better use of public transportation and non-motorized modes of transportation, like walking and cycling. All European cities feel the urge and necessity to plan a sustainable system of urban transportation in the interest of a healthier environment and liveable cities. The concept, methodology and framework of Sustainable Urban Mobility Plans (SUMP) have been worked out in 2007 in the international project "PILOT". These plans are prepared in several countries in Europe, taking into account local characteristics and existing national guidelines. In the regions and countries of Europe cities developed different systems for sustainable mobility, achieved different levels of planning. For example in the transportation planning practice in Hungary planning of sustainable mobility only exists as part of a transportation concept, or policy in a city, sometimes only mentioned in certain chapters of such documents. Nevertheless numerous cities in Hungary achieved success on the area of sustainable mobility and applied tools of green transportation planning without applying a systematic way. 
For example several large cities reconstructed their main square into a pedestrian area, realising the needs for creating more community surface and liveable city centres (for example centre of Győr, Pécs and Kaposvár). Other cities developed the public transportation system on a user friendly way (for example a tram line crosses the main pedestrian area in the city of Debrecen) and there is a very extensive need for building cyclepaths in several cities in Hungary.

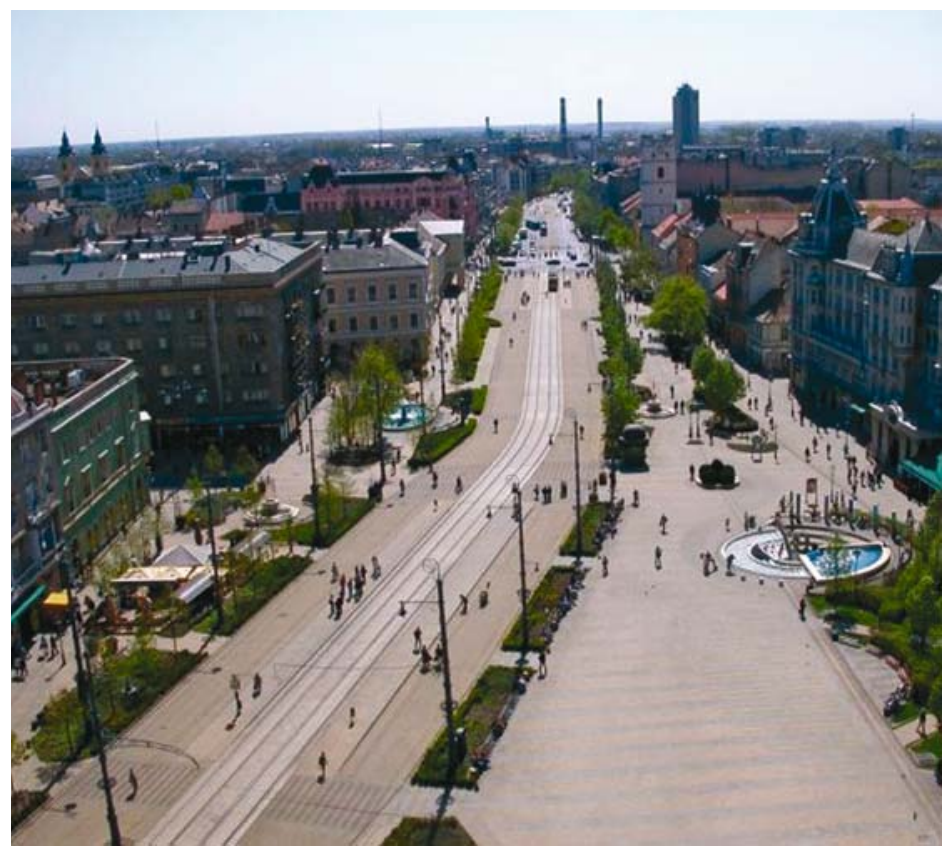

Photo 1. Kossuth Lajos Square in the city of Debrecen (Source: internet)

The QUEST-project which is being introduced in the article is aimed at a common evaluating system of urban sustainable mobility which is able to assist European cities in the work of planning transportation for the future and provides a type of labelling system which recognises the effort of cities to improve sustainable urban transport. This common tool which is basically a quality management system (the "QUEST-method") has been developed in a three year European project (May, 2011. - Nov. 2013.), under the Intelligent Energy Program Europe (STEER - Energy Efficient Transport).

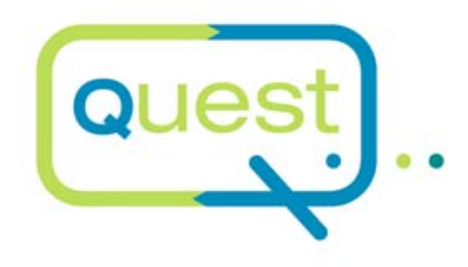

Figure 1. Logo of the QUEST-project 


\section{THE PROJECT}

The QUEST-Consortium was founded by 17 experts, consulting firms, research institutes, universities and international networks from 14 countries of Europe, aiming at assisting cities all over Europe in their process of establishing and improving a sustainable urban transportation strategy.

The name „QUEST" is the short form of „Quality management tool for Urban Energy efficient Sustainable Transport" expressing one of the main objectives of the project to work out an overall evaluating system for European cities. A system, which is able to take into account local characteristics as well. QUEST has been building further on existing quality management tools for urban transport originated from international projects (for example BYPAD, MEDIATE, EMAS, etc.).

The QUEST-project set up a quality management tool to evaluate urban mobility policies and improve sustainable urban mobility planning. QUEST is more than just a methodology for good policy making. It has the aim to support cities in actually making progress. In each participating city a specific improvement program was worked out by the local auditor, depending on the present quality level on sustainable urban transport. This was determined through an audit process.

From each countries 3-5 middle sized cities was chosen (and volunteered) to participate in the project. Number of inhabitants of the cities ranges between 50.000 and 250.000 inhabitants. Depending on the state of sustainable mobility planning in the city, three types of cities were distinguished: starters, climbers and champions.

The starter cities have little experience in active mobility planning. The climber cities apply some measures and tools of sustainable mobility, but not on a systematic way. Efforts has been focused on starter and climber cities, since champion cities have sufficient experience in sustainable mobility planning and are able to improve themselves. Champion cities (like Eindhoven from the Netherlands, San Sebastian from Spain and Bath from the UK) acted as good examples, inspirations and role models for other cities and they provided a test-area for the QUEST-method of evaluation which was worked out by the Consortium during the first half of the three year project.

The project itself consisted of the following main working phases:

\section{I) Working out and testing QUEST-tool}

This has been done by transportation experts and researchers of the Consortium as an overall method giving possibility to take local characteristics into account but consisting of a strong framework to be followed step by step.

Main points of the QUEST-tool are: evaluating current situation together with city personnel (audit), involving all stakeholders (could be different for each city), "brain storming" meetings on problem understanding and recommended solutions (future plans), discussions with city personals and decision makers, preparation and approval of Action Plans.

The tool was tested in partner cities and experiences as well as findings helped to modify and sophisticate the process before applying it in the 44 other European cities. 
During creation of the QUEST-method the followings were recognised as essential elements:

- following the process is important,

- local characteristics and needs have to be taken into account,

- self assessment cannot be missed,

- involvement of all stakeholders,

- political support is essential for success.

\section{II) Training national auditors}

After the QUEST-method was developed, tested and modified to meet the needs and requirements of the cities, for each participating country at least one auditor was trained during a three day training course in Frankfurt. The auditors learnt about aspects, important and essential processes of the QUEST-tool. These experts evaluated the urban transport policies in the QUEST cities and they guided the cities for developing the improvement program in a later stage of the project.

\section{III) Application of QUEST-tool in 50 European cities}

This most important phase of the project took about 6 months working closely with the cities, organising local and international workshops and as a result of the working phase Actions Plans for introducing new measures of sustainable mobility were worked out in each participating cities. During the project several workshops for cities and test cities were held in the partner cities where representatives from different participating cities shared problems and ideas for solutions. Networking was an important and very successful part of the project.

The next chapter will introduce this working phase and experiences in details.

\section{IV) Certification of sustainable urban mobility process in the cities.}

After the Actions Plans were developed by the auditor and the city staff, general assembly of the city (or other responsible body of the municipality) approved the Action Plan, indicating at least two measures whose implementation have to be started before the end of this year. With this step cities expressed their commitment for developing and improving a sustainable urban transportation system. At the Final Conference in Budapest, September this year all cities received their QUEST Certificate showing their participation in the project. Labelling is very important, since local improvement processes create media, public and political support.

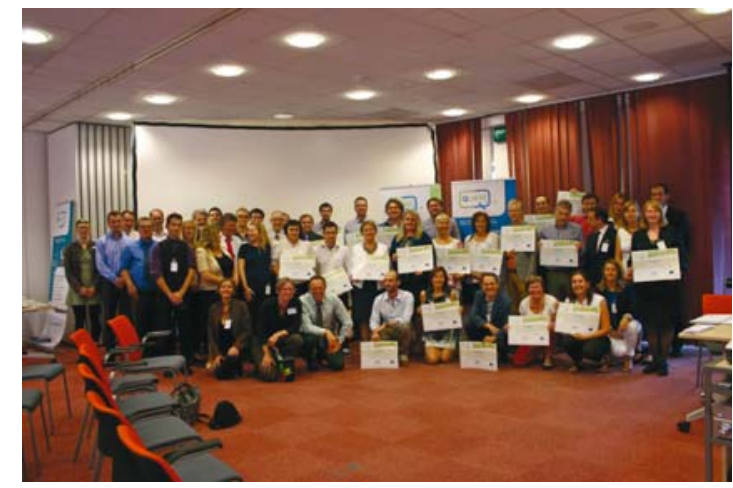

Photo 2. Participants of QUEST at the Final Conference 
Two European city-networks (POLIS and UCB) participated in the project organising dissemination of the QUEST-tool and exchange of experience between the QUEST-cities. A scientific board with three members supported the experts working on the project, safeguarding methodological aspects of total quality management in transport planning. Main co-ordinator of this large European project was Ligtermoet \& Partners from The Netherlands.

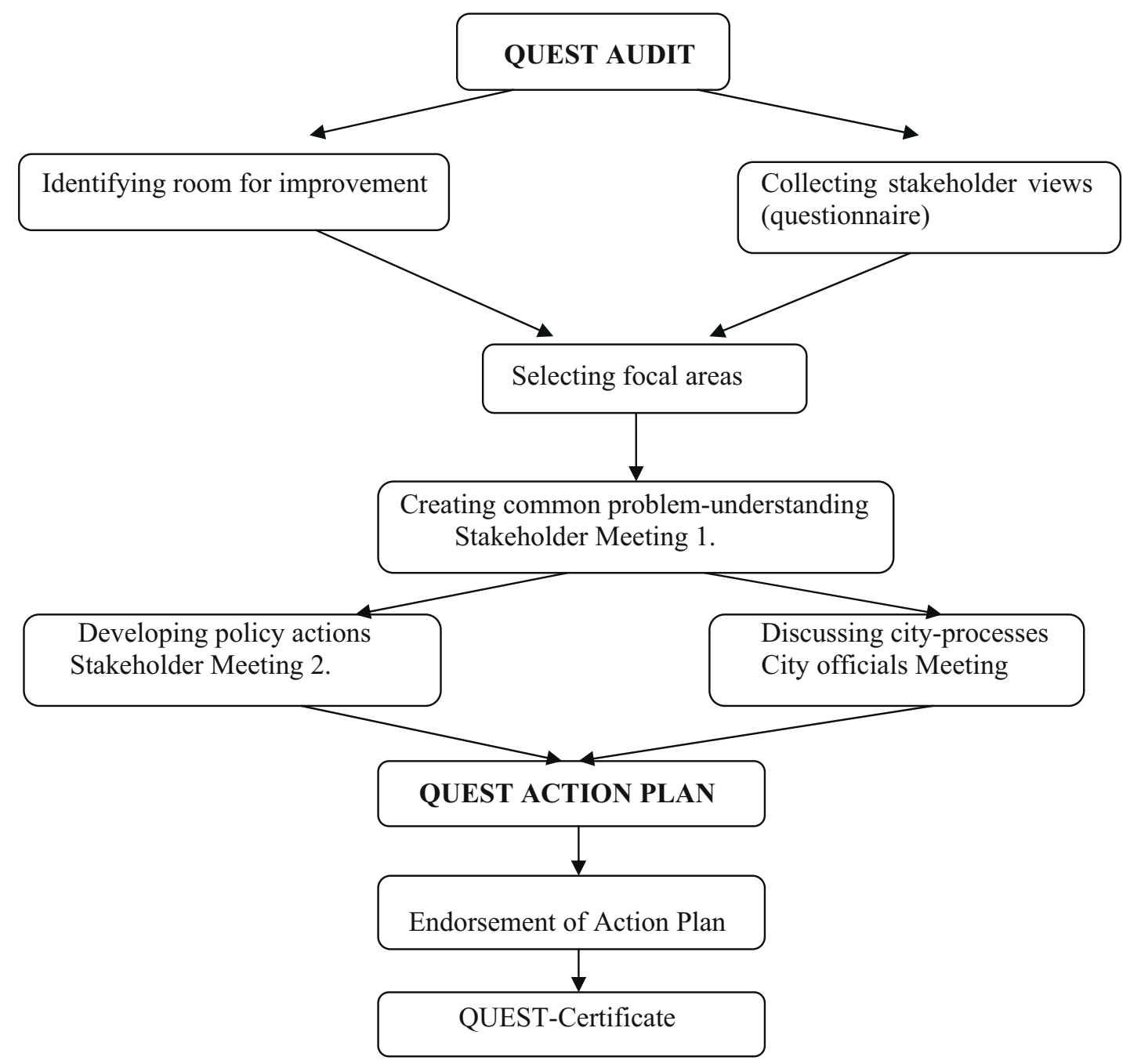

Figure 2. Ten main steps of the QUEST-method 


\subsection{Total quality management}

Total Quality Management (TQM) is an integrative philosophy of management for continuously improving the quality of products and processes. It represents an ever returning policy cycle of planning, implementation and evaluation. Commitment and leadership are essential component of TQM. In the field of sustainable urban mobility it means that the quality of processes is the responsibility of everyone involved in the process (planning and use/ consumption), requiring the involvement of management, experts, decision makers and users of the transportation system. In an idealistic system users' expectations should be met or even exceeded. TQM is now widely accepted as an approach in public sector administration.

This is the philosophy the QUEST-tool follows.

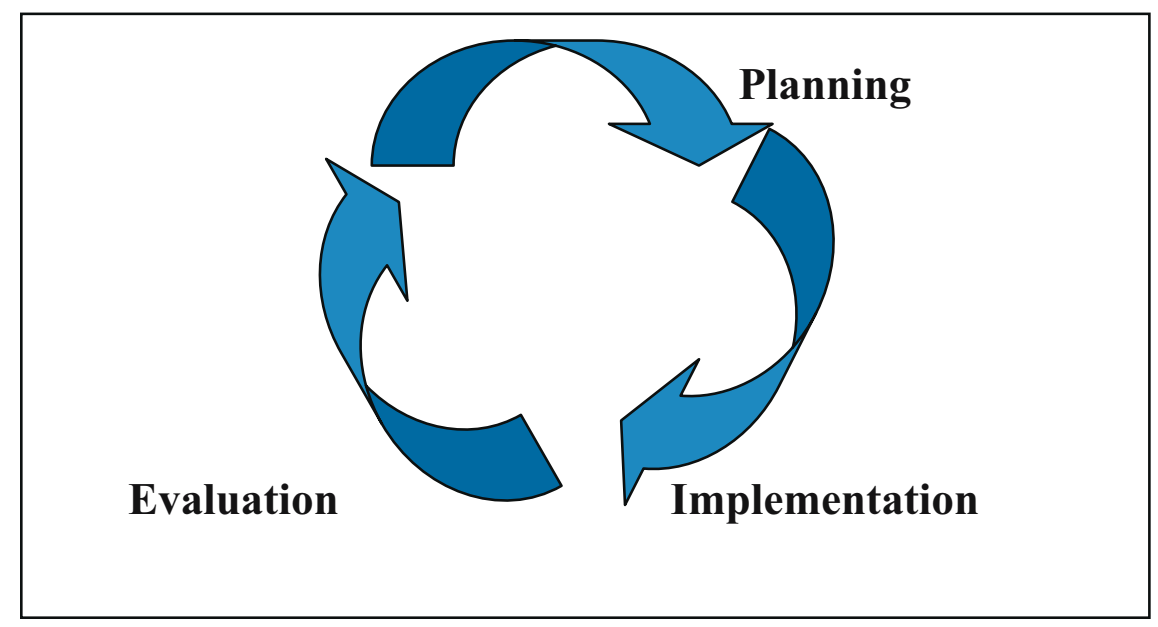

Figure 3. The policy-cycle according to Total Quality Management

\subsection{The process in the cities}

Two types of cities participated in the QUEST-project: partner (and test) cities and other QUEST-cities where the new method was used to assist the cities to improve their system of sustainable transportation.

Tasks for the cities during the project:

- Providing QUEST auditors with relevant information on urban transport plans, data on modal split, back ground transport policy

- Implementing QUEST tool: 3 working meetings with local actors and QUEST auditor

- Participating at QUEST workshops in a champion city

- Participating at the Final Conference where the QUEST quality labels were presented 
Benefits for these cities:

- Cities receive a report and quality label on the present quality level of the urban transport policy - External experts worked out a specific improvement program for the city with key elements to make progress in sustainable transport planning. These are the building stone to improve (or to work out) a sustainable urban mobility plan (SUMP).

- Cities participated at international workshops to exchange experiences with other cities.

- Cities became part of a European network of cities that exchange experiences on sustainable transport planning.

All together 50 European cities worked with the QUEST-method and 46 of them completed the process successfully. Four Hungarian cities volunteered to participate in the project: cities of Békéscsaba, Sopron, Székesfehérvár and Veszprém.

The QUEST method has 10 important steps, as follows:

\section{1. step: QUEST-audit}

In this stage, the national auditor worked with his/her cities to collect objective information on local transport policies, and compared these policies with the key elements of excellent policy practice. The result of this stage is the identification of strong and weak elements: the room for improvement. Collecting information was done by working through documents and plans regarding transportation solutions within the city, site visits and an interview with a city official personal, like head of departments, or so.

\section{2. step: Identification of room for improvement}

Based on these findings, the cities were assigned to a specific development track. This helped the QUEST auditor to adapt the following steps to the situation and capacity of the city. The next table shows a simple evaluation system.

\begin{tabular}{|l|l|}
\hline Area & City score (1-4) \\
\hline 1. Modal split & 3 \\
\hline 2. Processes regarding sustainable urban mobility policy & 3 \\
\hline 3. Facilitation for sustainable urban mobility policy & 2.5 \\
\hline 4. Sustainable urban mobility policy measures & 3 \\
\hline 5. Sustainable urban mobility policy priorities & 3 \\
\hline 6. Cycling & 3 \\
\hline 7. Public transport & 2 \\
\hline 8. Goods transport - freight & 2 \\
\hline 9. Green vehicles & 1 \\
\hline 10. Traffic circulation & 2.5 \\
\hline 11. Mobility management & 2.5 \\
\hline 12. Parking & 2.5 \\
\hline 13. Walking & 3.5 \\
\hline Average City Score & 2.58 \\
\hline
\end{tabular}

Figure 4. Evaluation of the cities' performance 


\section{3. step: Collecting stakeholders' views}

A wide group of stakeholders, including city staff, politicians, transport providers, transportation experts, business representatives and end-user groups were invited to share views on the city's performance with regard to sustainable mobility. A so-called self-assessment questionnaire was sent to at least 25 people representing these groups. The questionnaire contained 12 questions about transportation system and problems in the city and the people had to choose a preprepared answer showing their opinion. They could give their own opinion as well. Questions were asked about transportation policy of the city, lead personnel for implementation of this policy, possible participation of inhabitants in the planning process, needs of travellers, about different transportation modes, etc.

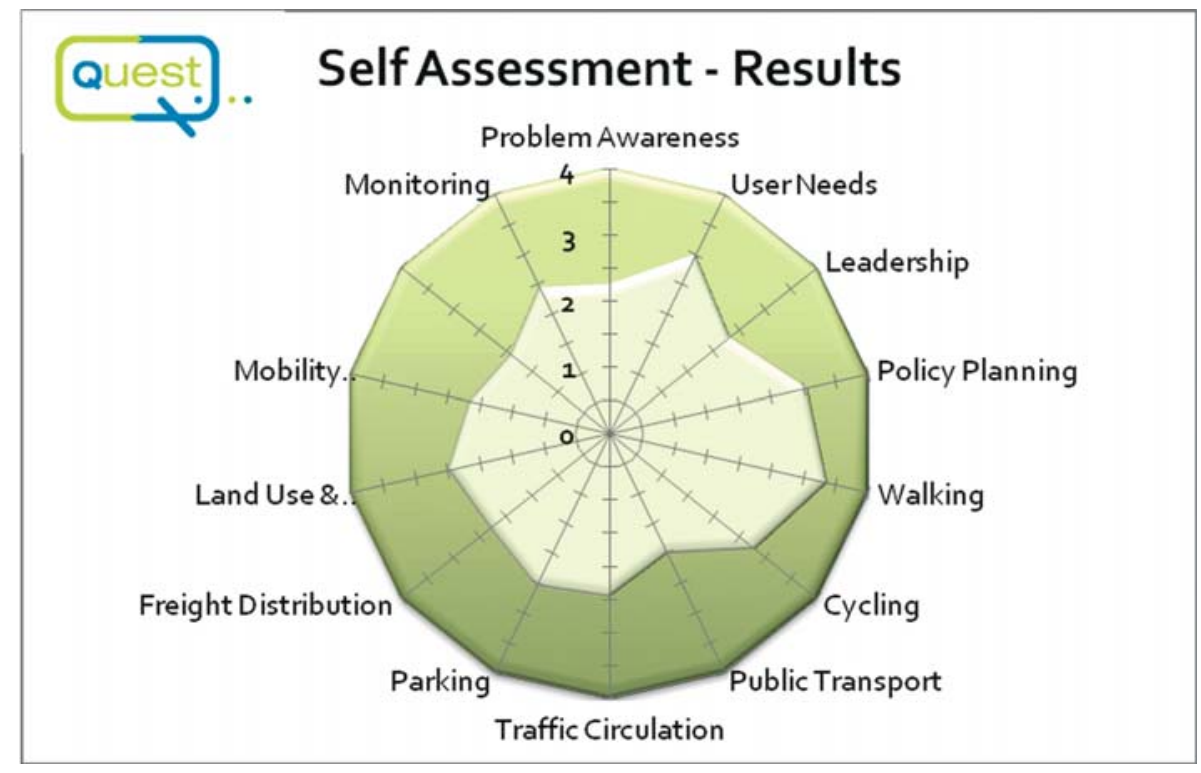

Figure 5. Self assessment results

\section{4. step: Choosing focal areas}

After the QUEST-audit and evaluation of the questionnaire, the city and the auditor selected three focal areas to concentrate on in the next phases of the process. Possible focal areas were: bicycle transportation, pedestrian transportation, public transportation, mobility management, parking, transportation of goods etc.

\section{5. step: Creating common problem-understanding (1. meeting)}

With participation of a smaller group of stakeholders mentioned above (12-15 persons) participated at a meeting at the City Hall to discuss current problems in the transportation system regarding sustainable mobility. Lively and very useful discussions took place in the cities with a common understanding of the existing problems, hot spots and future needs in the transportation systems. At least one decision maker was present at the meetings, sometimes a high ranking official in the city, for example vice mayor in the city of Veszprem followed the process closely and actively. 


\section{6. step: Developing policy actions (2. meeting)}

The same group of stakeholders were invited to a second meeting taking place about two weeks following the first meeting to discuss possible solutions for the identified problems and needs taking into account local characteristics. Differences in opinion were discussed in order to achieve consensus for commonly supported actions. The stakeholders discussed, and agreed on a set of actions that are widely supported by most stakeholders. The purpose was to develop a list of the most promising actions, according to scope for improvement, feasibility and cost/ benefit-estimation. These should be concrete actions that can be taken up over the coming years, and that aim for a specific result.

\section{7. step: Discussing city-processes (3. meeting)}

After the two meetings with the stakeholders, a separate meeting was held with the city personnel and decision makers to make sure that solutions and tools which stakeholders agreed on can be planned and implemented in the city. Support is needed from decision makers so implementation and budget will be available. So all chosen measures of sustainable mobility had to be part or at least had to meet requirements of the transportation policy in the city.

\section{8. step: Developing the Action Plan}

After two stakeholder meetings and a meeting with city officials, the auditor worked out the Action Plan for the city. This combined input from the audit, the self-assessment process and the three meetings, and clearly identified actions to improve the city's mobility policy and measures. The auditor based her recommendations on the specific local circumstances, took the specific needs of the policy makers and a national legislation into account. The ACTION PLAN selects the most promising measures needed to improve the energy efficiency of the urban transport system. The intensity of the improvement programme is directly linked to the quality level of sustainable urban mobility in the city. Action Plans were discussed within the cities and modifications were built in if it was required. Figure 6. shows a sample part of the recommended actions in the city of Békéscsaba. Action Plans contain much more than just a list of actions and possibilities, they introduce the current transportation situations and the plans in the city, the QUEST-process based on TQM, the importance and results of involving all stakeholders, and list all opinions which were expressed during discussions.

\section{Actions}

Short term measures

1. Evaluation of rehabilitation project in the city centre regarding transportation modes of sustainable mobility.

2. Setting up a working group to participate in "brain storming" before a large scale development would commence, strengthening communication between decision makers, professional experts and civil organisations.

3. Conciliation process of development of the cycling network has to be expanded in the interest of bringing closer planning aspects (for example a voting can be started on the website of the city about bicycle routes and timing of realisation). 
4. Review of road network in the interest of assigning cycling routes (to find suitable locations for different type of the cycling infrastructure, for example one-way streets).

5. Establishing relations with shop owners and possible sponsors regarding bicycle parking. It is important to include the Chamber of Commerce into the discussions with the businesses, strengthen their role and to find points of linkage.

6. To find possibilities of financial support for companies participating in placing cycling racks (possibility of reduced fares or taxes). Good practice from the city of Györ: support for building a certain type of cycle racks could be won by a tender, rate of support was $50 \%$. An example from the city of Szeged: "Adopt a cycle rack" campaign.

Figure 6. Sample of a List of Actions (full list contains of 25-30 recommendations)

\section{9. step: Endorsement of the Action Plan}

The City Councils endorsed the Action Plan and begun to implement the recommendations. It was up to the cities with their local stakeholders, to implement the actions, even long after the auditor has performed his or her tasks. When the City Council endorses the Action Plan, it commits itself to taking up the recommended actions.

\section{0. step: QUEST-Certification}

The city will be awarded with a QUEST Certificate. The QUEST Certificate indicates that the city has gone through the entire process of QUEST, and intends to implement the key findings. The Final Conference of the project was held in Budapest, on the 5th of September, 2013. QUEST-Certificates (quality labels) were handed out for the cities during this event.

\subsection{Experience with Hungarian cities}

Four Hungarian cities volunteered to take part in the QUEST-project: the cities of Békéscsaba, Sopron, Székesfehérvár and Veszprém. These (on a national scale) large cities all have different geographical situations, local characteristics and transportation habits beside the several similarities in the transportation system.

Hungarian partner of the QUEST Consortium, MOBIL CITY Consultancy acted as auditor in each of these cities, coordinating processes and developing the Action Plans working closely together with the experts working at the Municipalities, decision makers and other stakeholders.

For all Hungarian cities the following common characteristics can be identified:

- Sustainably Urban Mobility Plans rarely exist (methodology is being worked out on national level) only elements of it are built in transportation concepts.

A SUMP is a strategic plan designed to satisfy the needs of people and businesses in cities and their surroundings for a better quality of life. A SUMP defines a set of interrelated measures and is the result of an integrated approach which addresses all modes and forms of transport. 
A SUMP is a practical tool that can help improve sustainable policy. It builds on existing planning practices. (ELTISplus 2011: The State of the Art of Sustainable Urban Mobility Plans in Europe)

- Transportation policies (concepts) exist in large or middle sized cities only,

- Very few data is available (especially regarding MODAL SPLIT - proportions between different modes of transportation),

- Without political support even the best ideas will be useless and impossible to implement. This is why it was important that in the QUEST-cities decision makers supported the whole process and the endorsement of the Action Plans.

During the work with the cities application of the QUEST- method started with sending the municipalities the QUEST-audit questionnaire and evaluated the results afterwards. We had telephone interviews with experts at the city municipalities collecting more specific and actual information about local characteristics and processes. Then together with the cities we put together a list of participants for filling in the self assessment questionnaires which were sent out in e-mails. After questionnaires came back (on an average 25-35 people answered the questionnaires), Mobil City Consultancy evaluated them meanwhile the cities sent out invitations to the first city meetings for the participants we agreed on beforehand. All together three meetings were organized in the cities where two colleagues from the organization acted as moderator and expert. Usually the second meeting (about possible actions) followed the meeting on problem understanding in two weeks time. The third meeting for city personal and decision makers were held on the day of the second meeting.

Before the meetings we agreed on three focal areas of interest and discussions continued mainly about these subjects (but other aspects of sustainable mobility was mentioned as well) in all cities. In the four Hungarian cities these focal points were mainly parking, public transportation, mobility management, cycling and walking.

We collected several good experiences during the meetings:

- significant number of stakeholders participated with high enthusiasm and responsibilities. For each city there was at least one organisation which intended to take part in creating a new mobility culture in the city. In the city of Békéscsaba Chamber of Commerce is going to talk to shop owners about being involved in placing cycling racks in the city centre, in Veszprém the civil organisations support campaigns for walking, in Székesfehérvár companies in the Industrial Park will be working together with the Municipality taking part of the construction of cycle paths and in Sopron public transportation companies feel the need to help with organisation of integrated public transport.

- civil organisations are very active and have ideas for transportation solutions,

- Chamber of Engineers and Chamber of Commerce have their active role in the process,

- more communication is needed between stakeholders, users and politicians

(dissemination of results as well)

- campaigns are very important (especially for children)

- isolated initiatives have to be organised

- intention of participating in EU-projects (networking). 
After the meetings as a first task a List of Actions were prepared and send to the cities to approve or modify them meanwhile the rest of the Action Plan was written for the cities. After completion the final version of the documents, general assembly of the cities approved the Action Plans.

The Action Plans consist of description of the whole QUEST-method and process, including current transportation situation in the city, results of the audit, the questionnaires and the stakeholder meetings and was completed by the list of the recommended actions. Major recommendations were about soft measures, training, campaigns, involving major companies and civil organisations, communications, etc. Recommendations were based on the major elements of sustainable mobility and took local characteristics into account.

Our organization assisted the Hungarian cities with the tasks of participating at the international workshops, helping them with communication and in preparation of the presentations.

Before the Final Conference of the project a Hungarian QUEST-seminar was held in September 2013. The Hungarian auditor was responsible for organisation of this event, where several cities, transportation and land use experts, public transportation companies participated and learnt about the QUEST-method.

In the last months of the project QUEST-leaflets were prepared in several languages introducing the project and the method the Consortium intends to work with in the future. In the Hungarian leaflet, the participating Hungarian cities had a chance to introduce their successes and plans.

\section{RESULTS}

The main outcomes of the QUEST-projects are the followings:

- A European Quality Label (Certificate) for urban sustainable transport.

- A quality management tool for developing and improving sustainable urban mobility policies/plans.

- An audit of urban mobility in 46 midsized EU-cities.

- Improvement program in these cities (mainly starter and climber cities).

- Site visits to successful champion cities for other cities.

- Training sessions for future QUEST-auditors.

- Cities went through their mobility policy and were then able to identify needs for improvement.

- Cities form their stakeholder groups, deepened and enlarged partnerships.

- Cities were assisted in bringing proposals to political level and achieving approval of necessary actions.

- Cities participated in QUEST exchange events (networking).

- QUEST is especially useful for small and medium-sized cities by setting up and further developing their sustainable mobility policies and actions.

- QUEST helps cities to identify which measures are effective in achieving energy savings in transport, and which are possible to achieve (i.e. QUEST helps cities to make the right choices).

- The QUEST Certificate can be used to demonstrate a city's engagement in sustainability, for the attention of national or European funding authorities. 


\section{CONCLUSION}

For a transportation planner working in an international consortium bringing together 17 partners from 14 European cities is a special experience. Creating a tool which can be applied in any European middle sized cities with good result is a rear task for any team of experts. After completion of the project we can confidently say that this is a very successful project since the tool which has been worked out was applied in almost 50 European cities and they all found it useful in the process of working out solutions for sustainable mobility. The best experience for all the cities (and the auditors) was the fact how important and useful to involve a group of stakeholders representing all aspects of planning during the process. Real brain storming occurred at the meetings.

\section{About the national part of the project (Hungarian contribution):}

First experience during the project was a very positive one: it was not difficult to find four cities which were interested and intended to join the project. During the process of QUEST (especially at the meetings) a real brain storming was formed and many people were ready to participate with ideas. The meetings during the project have brought together stakeholders who should have been working together and sharing information on the issues of sustainable mobility development for a long time.

The auditor worked in the four cities almost parallel (due to shortage of time) which turned out to be a real advantage, since experience and ideas in one city acted as a good trigger for discussions in other cities (taking into account local differences of course).

In Hungary sustainable mobility planning is not yet as evident as in several other countries, this is why the success of QUEST (very good professional work within and with the cities, useful participation of many stakeholders, political support) means a good starting point in mobility planning. International networking is very useful and important for the cities and this project gave these cities a good opportunity for sharing experiences with other European cities.

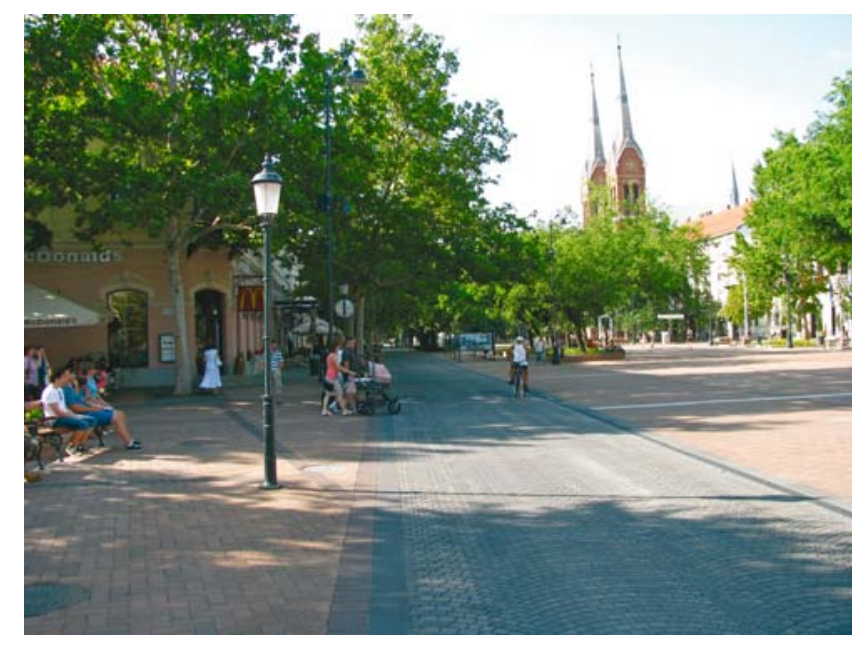

Photo3. Szent István Square in the city of Békéscsaba 
In the questionnaires sent out for the stakeholders there were some expressions which an average Hungarian user of transportation systems is not very familiar with, but it did not cause any problem during the process. In the beginning of all meetings we discussed what we mean by sustainable mobility and this way discussions were quite clear for everyone. The questionnaires are very useful for collecting viewpoints, which are definitely good starting points at the meetings. Stakeholders filling in the questionnaires did it thoughtfully, they had many comments and recommendations to make.

Cities have chosen the focal points based on the experience and interest they had before the audit, but it usually matched the self assessment results. During the meetings not only the focal areas were discussed (since areas of sustainable mobility are closely connected and should be seen as a system). We found that restricting parking in city centres is a sensitive topic in all cities.

Interest for the project in the cities were quite large and surprising, not only experts but user groups participated very actively. In some cities representatives of large employers were present and active during the process. Political support for the project was more than we expected beforehand, each city felt the Action Plan being important enough to have approval of the General Assembly in the city. Relations and discussions among the cities might happen more often due to the success (and usefulness) of the project.

The Consortium intends to disseminate the QUEST-method through national and international conferences and trainings on urban transportation, urban development and seminars for decision makers.

The greatest success of the whole project is that all participants share the same general opinion: the QUEST-tool itself proved to be a real practical and useful tool, triggering development in the area of sustainable mobility.

Further information about the project can be found on the website of the project: www.quest-project.eu

\section{REFERENCES}

[1] „Quality Management tool For Urban Energy efFicient Sustainable Transport” - INFormation leaflet about the QUEST-PROJECT, 2013.

[2] „QUEST-report and Action Plan” for the city of Békéscsaba, Mobil City Consultancy, 2013.

[3] WWW.QUEST-PROJECT.EU

[4] WWW.MOBILITYPLANS.EU 